\title{
Prevalence and antimicrobial sensitivity of Escherichia coli and Salmonella species in field cases of rabbit intestinal coccidiosis treated with prebiotic
}

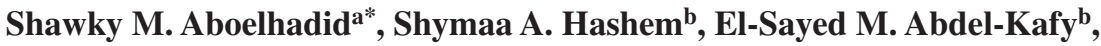 \\ Abdel-Azeem S. Abdel-Bakic, Saleh Al-Quraishyd, Ahmed Hussien Abed ${ }^{\text {h }}$, Asmaa A. Kamel ${ }^{\text {a }}$
}

\begin{abstract}
Coccidian infection may promote the proliferation of gut bacteria of the family Enterobacteriaceae. Bacterial infections by members of this family in rabbits can induce a negative impact on their health and lead to high mortality, especially in young individuals. This study aimed to investigate the effect of prebiotic treatment on Escherichia coli and Salmonella species during natural intestinal coccidiosis in rabbits. Forty-five rabbits were selected from a rabbit farm in Beni-Suef, Egypt. Out of the 45 rabbits, 15 were coccidia-free and used as the negative control group (NC group) and 30 were naturally infected with coccidia. The infected rabbits were randomly divided into two equal groups, the positive control group (PC) and the prebiotic treated group (PT) which was orally treated with prebiotic for 8 successive days. Faecal oocyst count was assessed daily during the course of treatment. At 8 days post-treatment, 5 rabbits from each group were euthanised for the microbiological examination of the intestinal tract. On day 8 posttreatment, the PT group showed a significant $(P \leq 0.05)$ reduction in the oocyst count $\left(5.33 \times 10^{3} \pm 0.89\right)$ with a significant $(P \leq 0.05)$ decline in the prevalence of $E$. coli and Salmonella (66.7 \% and $26.4 \%$, respectively). The PC group showed highly a significant oocyst count $\left(21.67 \times 10^{3} \pm 0.82 \mathrm{OPG}\right)$, with a significant increase in the prevalence of E. coli and Salmonella $(86.7 \%$ and $46.7 \%$, respectively). The NC group remained coccidian free and exhibited only E. coli with no Salmonella infection. The in vitro susceptibility test showed that $E$. coli isolates were highly resistant to most of the tested antimicrobials while Salmonella isolates showed variable resistance profiles. In conclusion, the prebiotic treatment significantly reduced the prevalence of E. coli and Salmonella infections coexisted with intestinal coccidiosis naturally infected rabbits.
\end{abstract}

Key words: rabbits, prebiotic, coccidiosis, Salmonella, E. coli, antimicrobial sensitivity.

\section{INTRODUCTION}

Rabbit production is a fast growing livestock industry worldwide. Rabbit meat is considered a source of animal protein that can solve the problem of the red meat shortage all over the world (Dalle and Szendro 2011). Digestive infections represent one of the main pathological problems and are responsible for significant economic losses in rabbit breeding facilities (Saravia et al 2017). Domestic rabbits are susceptible to a number of infectious diseases: parasitic, bacterial and viral (Langan et al 2000, Lennox and Kelleher 2009).

Rabbit coccidiosis is a disease caused by protozoan parasites of the genus Eimeria (Apicomplexa: Eimeriidae) (Pakandl 2009). Coccidiosis is mainly detected in young rabbits aged one to three months, especially after weaning, and it causes enteritis and diarrhoea and in severe cases infection may lead to death (Pakandl and Hlaskova 2007,

Received: 02.08.2021.

Accepted: 21.10.2021.

aParasitology Department, Faculty of Veterinary Medicine, Beni-Suef University, Beni-Suef, Egypt.

${ }^{b}$ Animal Production Research Institute, Agricultural Research Center, Dokki, Egypt

'Zoology Department, Faculty of Science, Beni-Suef University, Beni-Suef, Egypt.

dZoology Department, College of Science, King Saud University, Riad, Saudi Arabia.

${ }^{\mathrm{e} B a c t e r i o l o g y}$, Mycology and Immunology Department, Faculty of Veterinary Medicine, Beni-Suef University, Beni-Suef, Egypt.

*Corresponding author: SM Aboelhadid; shawky.abohadid@ vet.bsu.edu.eg
Pakandl 2009, Papeschi et al 2013, El-Ashram et al 2019). Previous literature reported that coccidiosis has been associated with secondary bacterial and viral infections, which were common causes of mortality (Taylor et al 2003, Dorota et al 2012, Aboelhadid et al 2021). Rashwan and Marai (2000), Bortoluzzi et al (2019) and Madlala et al (2021) postulated that the coccidian infection may enhance the proliferation of Gram-negative bacteria of the family Enterobacteriaceae in the gut. Bacterial infections in rabbits can negatively affect the body condition and cause high mortality, especially at young ages (Zahraei et al 2010).

Escherichia coli $(E$. coli) is a common commensal bacterium of the gastrointestinal tract of warm-blooded animals. However, in an immune-suppressed host, certain $E$. coli strains become virulent and cause diarrheal and extraintestinal diseases (Croxen et al 2013). Hamed et al (2013) reported hemorrhagic colitis and diarrhoea in newborn New Zealand rabbits infected with E. coli. Also, Salmonella enterica infection in rabbits is considered a potential risk associated with this animal species (Suelam and Reda 2015). Its occurrence among domestic rabbits is probably variable (Rodriguez-Calleja et al 2006). According to Lim et al (2012), the prevalence of Salmonella species in rabbits ranged from 6 to $9 \%$. It can occasionally cause a severe disease condition with a high mortality rate (Suelam and Reda 2015).

Antimicrobial therapy is one of the worldwide primary controls for the reduction of both incidence and mortality associated with bacterial diseases including colibacillosis and Salmonellosis in poultry (Hassan et al 2018, Radwan et al 2021). In-vitro antimicrobial susceptibility tests 
provide valuable guidance in the choice of appropriate drug treatment (Radwan et al 2021) and are very useful for detecting the MDR isolates. Recently, the phenomenon of antimicrobial resistance has evolved and spread out in large geographic areas. Therefore, the appropriate antimicrobials should be selected based on their susceptibility which could be detected by laboratory examination. Also, the challenge of antimicrobial resistance has increased the importance of searching for new compounds as alternative antimicrobials. Therefore, considerable effort has been devoted to investigating natural products to discover and develop new antimicrobial agents that are effective, easily accessible and affordable, with less side effects.

Prebiotics are non-digestible food components that promote the growth of beneficial bacteria in the digestive system and the host defence against infections (ElAbasy 2002, Sohail et al 2012). It was also observed that prebiotic consumption reduced the establishment of Salmonella in the course of hen moulting (Donalson et al 2008). Abdelhady and El-Abasy (2015) found that dietary supplementation of prebiotic and probiotic reduced mortality and overcame the adverse clinical signs in rabbits experimentally infected with Pasteurella multocida. Bio-Mos®, a prebiotic used in the animal husbandry industry, exhibited a suppressing effect on enteric pathogens and modulated the immune response of chickens and turkeys (Waldroup et al 2003, Kocher et al 2005). Mannan-oligosaccharide is now widely accepted as one of the most effective alternatives to antibiotics and growth promoters (Ferket et al 2002).

The present study aimed to investigate the effects of mannan-oligosaccharide (MOS) prebiotic supplementation on the coexistence of E. coli and Salmonella species in rabbits naturally infected with intestinal coccidiosis.

\section{MATERIAL AND METHODS}

The study was carried out on a rabbit farm at Sedes Station of Animal Production and Agriculture Research, Beni-Suef, Egypt. A total of 45 V-Line breed weaned rabbits, male and female, aged 30 to 35 days were selected for the experiment. Out of the 45 rabbits, 30 were naturally infected with intestinal coccidiosis (with the same average of oocyst count) and 15 were coccidian free. The infected rabbits showed the clinical signs of intestinal coccidiosis, e.g. diarrhoea, inappetence, abdominal bloating, and weight loss. These signs of coccidiosis were confirmed by detection and counting the oocysts in faeces by McMaster slide. All rabbits were examined individually and rabbits with oocyst count over $2.5 \times 10^{4}$ oocysts per gram faeces (OPG) were considered diseased according to Ogolla et al (2018). Each rabbit was housed in an individual wire mesh cage with optimum conditions and fed ad libitum with commercial rabbit feed (anticoccidial free). The clinically infected rabbits $(n=30)$ were divided into two groups of 15 rabbits each; the first group was kept with no treatment and served as the positive control group (PC) while the second group was treated with prebiotic and served as the prebiotic treated group (PT) at a dose of $2 \mathrm{~g} / \mathrm{L}$ for 8 successive days. The uninfected rabbits $(n=15)$ served as the negative control group (NC). On day 8 post treatment, 5 rabbits from each group were humanely slaughtered for microbiology examination. The rabbits were handled and euthanised with the least distressful method which was cervical dislocation because they were not heavy weight (Walsh et al 2017). Death was verified by lack of breathing, lack of palpable heartbeat and fixed dilated pupil.

The study was approved by the ethical committee of Beni-Suef University (BSU- 0365/2018), Egypt. The used prebiotic was mannan-oligosaccharide (MOS) which derived from the cell wall of Saccharomyces cerevisiae (Bio-Mos®, Alltech, Nicholasville, USA).

\section{FAECAL SAMPLE COLLECTION AND ESTIMATION OF} OOCYST COUNT

Fresh faeces of each rabbit were collected daily during the course of treatment in all groups and the faecal oocyst count was estimated per gram of faeces using McMaster chamber according to Schito et al (1996). In brief, faecal pellets were weighed and diluted 10- fold in $2.5 \%$ potassium dichromate $(\mathrm{w} / \mathrm{v})$. For oocyst flotation, the mixture was vortexed and diluted in saturated sodium chloride. Finally, $300-\mu l$ of this dilution was loaded into the McMaster chamber, where the oocysts were allowed to float free of debris for 3-5 minutes before being counted. The diagnosis of different encountered Eimeria species was based on the descriptions mentioned by Eckert et al (1995). The following coccidian species were confirmed in the infected rabbits; E. media, E. magna, E. intestinalis, E. flavescens and E. perforans.

\section{INTESTINAL SAMPLES AND BACTERIOLOGICAL EXAMINATION}

Samples. Intestinal swabs were collected from the jejunum, ileum, and cecum of all euthanised rabbits (15 in total, 5 from each group). Accordingly, a total of 45 intestinal swab samples (15 from each group) were collected aseptically for bacteriological examination and screening of the presence of E. coli and Salmonella spp. The collected samples were transferred promptly, in an ice tank, to the microbiology laboratory.

Bacteriological isolation. Escherichia coli was isolated according to the protocol described by Radwan et al (2021). The collected samples were aseptically inoculated into MacConkey's broth and incubated aerobically at $37^{\circ} \mathrm{C}$ for $24 \mathrm{hrs}$. Then, a loopful of each broth cultures was streaked onto tryptone soy agar and MacConkey's agar and incubated aerobically at $37^{\circ} \mathrm{C}$ for $24-48 \mathrm{hr}$. The lactose fermenting (pink) colonies were inoculated onto 
eosin methylene blue (EMB) agar medium and incubated at $37^{\circ} \mathrm{C}$ for $18-24 \mathrm{hrs}$.

Salmonella was isolated according to the protocol described by Hassan et al (2018). The collected samples were inoculated into selenite-F broth and incubated at $37 \mathrm{C}$ for 18-24 hrs. Then, a loopful of each culture was streaked out onto MacConkey's agar then the non-lactose fermenter (pale) colonies were streaked onto xylose lysine deoxycholate (XLD) and Salmonella-Shigella (SS) agar media and incubated at $37 \mathrm{C}$ for $18-24 \mathrm{hrs}$.

\section{IDENTIFICATION OF E. coli AND Salmonella ISOLATES}

Morphological and biochemical identification. All the recovered isolates were identified by microscopic examination of Gram's stained smears, colonial morphology and biochemical tests according to Collee et al (1996) and Quinn et al. (2002) using the following tests; oxidase, catalase, urease, $\mathrm{H}_{2} \mathrm{~S}$ production on TSI, and citrate utilisation. Moreover, a motility test in semisolid agar was applied.

Identification by using API20E kit. Escherichia coli and Salmonella isolates were also confirmed biochemically by using the API 20E system (BioMérieux, Marcy-l'Étoile, France) according to the manufacturer's instructions. Bacterial strains fully identified by the Department of Bacteriology, Mycology, and Immunology, Faculty of Veterinary Medicine, Beni-Suef University, Egypt were used as a positive control in API kits.

\section{SEROLOGICAL IDENTIFICATION OF BACTERIAL ISOLATES}

Serogrouping of E. coli isolates. Escherichia coli isolates were serogrouped by slide agglutination test using standard polyvalent and monovalent $E$. coli antisera according to Quinn et al (2002).

Serotyping of Salmonella. Salmonella isolates were serotyped by slide agglutination test using diagnostic polyvalent and monovalent $\mathrm{O}$ and $\mathrm{H}$ Salmonella antisera following the Kauffman-White- Le Minor scheme (Grimont and Weill 2007).

\section{ANTIMICROBIAL SUSCEPTIBILITY TESTING}

All E. coli and Salmonella isolates were tested for their antimicrobial susceptibility to 14 different antimicrobial discs (Oxoid, Basing Stoke, UK) including; amoxicillin (10 $\mu \mathrm{g})$, neomycin $(15 \mu \mathrm{g})$, tetracycline $(30 \mu \mathrm{g})$, sulphamazoletrimethoprim $(25 \mu \mathrm{g})$, nalidixic acid $(30 \mu \mathrm{g})$, gentamicin $(10 \mu \mathrm{g})$, levofloxacin $(5 \mu \mathrm{g})$, florfenicol $(30 \mu \mathrm{g})$, colistin sulphate $(10 \mu \mathrm{g})$, ciprofloxacin $(5 \mu \mathrm{g})$, amikacin $(30 \mu \mathrm{g})$ and flumequine $(25 \mu \mathrm{g})$. An antimicrobial susceptibility test was applied using the disc diffusion method on Muller Hinton agar according to CLSI (2016). The antimicrobial susceptibility was based on the induced inhibition zones according to the guidelines of the CLSI (2016). Resistance to three/or more antimicrobials of different categories was taken as multidrug resistance (MDR) according to Chandran et al (2008).

\section{STATISTICS}

The data were summarised using a descriptive frequency and percentage for quantitative values. The relationship between data were tested by the Chi-square test for quantitative variables, and $p$-values were calculated. The oocysts per gram of faeces (OPG) were statistically analysed using ANOVA tests and subsequent Duncan's multiple range tests. Results were expressed as means \pm SE. Probability of values less than $0.05(P \leq 0.05)$ was considered significant.

\section{RESULTS}

FAECAL OOCYST COUNT AND PREVALENCE OF E. coli AND Salmonella ISOLATIONS IN DIFFERENT GROUPS

Faecal oocyst count revealed a gradual reduction from day zero (day of treatment) until day 8 post treatment in PC and PT groups. There was a significant $(P \leq 0.05)$ decrease in oocyst count $\left(5.33 \pm 0.89 \times 10^{3}\right)$ in rabbits treated with prebiotic (PT) when compared with those non-treated (PC) $\left(21.67 \pm 0.82 \times 10^{3}\right)$ (figure 1). Meanwhile, the NC group revealed no oocysts in the faeces (table 1). During the period of treatment, the clinical signs were less severe

Table 1. Prevalence of E. coli and Salmonellae isolation in the examined rabbit samples in different groups.

\begin{tabular}{lccccccc}
\hline \multirow{2}{*}{ Group } & \multirow{2}{*}{ No. of samples } & \multicolumn{2}{c}{ E. coli isolation } & Salmonella isolation & $\mathrm{X}^{2}$ (df) & $\mathrm{P}^{*}$ \\
\cline { 3 - 7 } & & No. & $\%$ & No. & $\%$ & $22.003(2)$ & 0.000 \\
\hline Negative control (NC) & 15 & 7 & 46.7 & 0 & 0 & & \\
Positive control (PC) & 15 & 13 & 86.7 & 7 & 46.7 & & \\
Prebiotic treated (PT) & 15 & 10 & 66.7 & 4 & 26.7 & & \\
Total & 45 & 30 & 66.7 & 11 & 24.4 & & \\
\hline
\end{tabular}

$\%$ : was calculated according to the number (No.) of tested isolates $(\mathrm{n}=30)$

$\mathrm{X}^{2}$ : Chi-square. df: degree of freedom. $* P \leq 0.05$ is significant. 
in the PT group than in the PC group. Rabbits in the PT group suffered from watery diarrhoea. However, rabbits in the PC group displayed diarrhoea with mucus, bloating, inappetence, and dullness. The rabbits in the NC group appeared normal with no clinical signs of disease.

On the other hand, the overall prevalence of $E$. coli and Salmonella isolates was $66.7 \%$ and $24.4 \%$, respectively (table 2). The results showed a significant reduction in the prevalence $(P \leq 0.05)$ of $E$. coli and Salmonellae isolates in rabbits of the PT group when compared with those of the PC group. In the PC group, 13 E. coli and 7 Salmonellae isolates were recovered with a prevalence of $86.7 \%$ and $46.7 \%$, respectively. Meanwhile, 10 E. coli and 4 Salmonellae isolates were detected in the PT group with a prevalence of $66.7 \%$ and $26.7 \%$, respectively. Regarding the NC group, only $7 \mathrm{E}$. coli isolates with a prevalence of $46.7 \%$ were found with no detection of any Salmonellae.

\section{SEROLOGICAL IDENTIFICATION OF BACTERIAL ISOLATES}

Serogrouping of E. coli isolates and their distribution in different organs. Out of $30 \mathrm{E}$. coli isolates, $7 \mathrm{O}$-serogroups

Table 2. Serogroups of E. coli recovered from the intestinal tissue samples of the examined rabbits.

\begin{tabular}{lcc}
\hline E. coli serogroups & No. of isolates & $\%$ \\
\hline $\mathrm{O}_{78}$ & 11 & 36.7 \\
$\mathrm{O}_{125}$ & 6 & 20 \\
$\mathrm{O}_{152}$ & 4 & 13.3 \\
$\mathrm{O}_{158}$ & 3 & 10 \\
$\mathrm{O}_{114}$ & 2 & 6.7 \\
$\mathrm{O}_{115}$ & 2 & 6.7 \\
$\mathrm{O}_{168}$ & 2 & 6.7 \\
Total & 30 & 100 \\
\hline
\end{tabular}

$\%$ : was calculated according to the total number (No.) of isolates $(n=30)$. were identified and $\mathrm{O}_{78}$ was the most prevalent representing $36.7 \%$ (table 3). The distribution of E. coli serogroups $(\mathrm{n}=30)$ in the different organs in all groups is shown in table 4.

Serotyping of Salmonella isolates and their distribution in different organs. Out of 11 Salmonella isolates, 3 Salmonella enterica Subsp. enterica serotypes were identified. The serotype $S$. Macclesfield was the most prevalent with 5 isolates representing $45.5 \%$ (table 5). The distribution of Salmonella enterica serotypes $(\mathrm{n}=11)$ in different organs in all groups is shown in table 5. No Salmonella isolates were recovered from rabbits in the NC group.

\section{ANTIMICROBIAL SUSCEPTIBILITY TESTING OF E. coli AND Salmonellae RECOVERED FROM THE RABBITS INTESTINAL SAMPLES}

Results of in vitro susceptibility testing showed that $E$. coli isolates were highly resistant to most of the tested antimicrobials and completely resistant to neomycin (100\%) (table 6). Meanwhile, moderate sensitivities were recorded against colistin sulphate $(50 \%)$ followed by ciprofloxacin $(43.3 \%)$ and amikacin (40\%) (table 6). MDR was detected in $27 \mathrm{E}$. coli isolates $(90 \%)$.

On the other hand, Salmonella isolates $(n=11)$ were highly resistant to sulphamethoxazol-trimethoprim and

Table 4. Serotypes of Salmonellae recovered from the intestinal tissue samples of the examined rabbits.

\begin{tabular}{lcc}
\hline Salmonella serotypes & No. of isolates & $\%$ \\
\hline S. Macclesfield & 5 & 45.5 \\
S. Canada & 3 & 27.3 \\
S. Kisangani & 3 & 27.3 \\
Total & 11 & 100 \\
\hline
\end{tabular}

$\%$ : was calculated according to the total number (No.) of isolates $(\mathrm{n}=11)$.

Table 3. Distribution of E. coli serogroups in different organs in different groups.

\begin{tabular}{lcccc}
\hline Group & E. coli serogroups & Organ of isolation & No. of isolates & $\%$ \\
\hline \multirow{2}{*}{ NC } & $\mathrm{O}_{152}$ & Ilium & 4 & 13.3 \\
& $\mathrm{O}_{115}$ & Caecum & 2 & 6.7 \\
& $\mathrm{O}_{125}$ & Jejunum, Ilium and caecum & 1 & 3.3 \\
PC & $\mathrm{O}_{78}$ & Jejunum and Ilium & 3 & 23.3 \\
& $\mathrm{O}_{158}$ & Jejunum & 2 & 6.7 \\
& $\mathrm{O}_{125}$ & Jejunum, Ilium and caecum & 10 & 3.3 \\
PT & $\mathrm{O}_{114}$ & Jejunum & 4 & 13.3 \\
& $\mathrm{O}_{78}$ & Jejunum and Ilium & 3 & 10 \\
Total & $\mathrm{O}_{125}$ & Jejunum, Ilium and caecum & 2 & 6.7 \\
\hline
\end{tabular}

$\%$ : was calculated according to the total number (No.) of isolates $(n=30)$. 
Table 5. Distribution of Salmonella serotypes in different organs in different groups.

\begin{tabular}{lcccc}
\hline Group & Salmonella serotypes & Organ of isolation & No. of isolates & $\%$ \\
\hline NC & Negative & Negative & Negative & Negative \\
& S. Kisangani & Ilium & 3 & 27.3 \\
PC & S. Macclesfield & Caecum & 2 & 18.2 \\
& S. Canada & Ilium, Jejunum & 2 & 18.2 \\
& & & 3 & 27.3 \\
PT & S. Macclesfield & Caecum & 1 & 9.1 \\
Total & S. Canada & Ilium, Jejunum & 11 & 100 \\
\hline
\end{tabular}

$\%$ : was calculated according to the total number (No.) of isolates $(n=11)$.

Table 6. Antimicrobial susceptibility testing of E. coli and Salmonellae recovered from the intestinal tissue samples of the examined rabbits.

\begin{tabular}{|c|c|c|c|c|c|c|c|c|c|c|c|c|c|}
\hline \multirow{3}{*}{ Antimicrobial disc } & \multirow{3}{*}{$\begin{array}{l}\text { Disc content } \\
\quad(\mu \mathrm{g})\end{array}$} & \multicolumn{6}{|c|}{ E. coli $(\mathrm{n}=30)$} & \multicolumn{6}{|c|}{ Salmonella $(\mathrm{n}=11)$} \\
\hline & & \multicolumn{2}{|c|}{$\mathrm{R}$} & \multicolumn{2}{|c|}{ I } & \multicolumn{2}{|c|}{ S } & \multicolumn{2}{|c|}{$\mathrm{R}$} & \multicolumn{2}{|c|}{ I } & \multicolumn{2}{|c|}{ S } \\
\hline & & No & $\%$ & No & No & $\%$ & No & No & $\%$ & No & $\%$ & No & $\%$ \\
\hline Amoxicillin & 10 & 20 & 66.7 & 7 & 23.3 & 3 & 10 & 8 & 72.7 & 3 & 27.3 & 0 & 0 \\
\hline Neomycin & 15 & 30 & 100 & 0 & 0 & 0 & 0 & 3 & 27.3 & 8 & 72.7 & 0 & 0 \\
\hline Tetracycline & 30 & 23 & 76.7 & 5 & 16.7 & 2 & 6.7 & 4 & 36.4 & 5 & 45.5 & 2 & 18.2 \\
\hline $\begin{array}{l}\text { Sulfamethoxazole- } \\
\text { trimethoprim }\end{array}$ & 25 & 24 & 80 & 6 & 20 & 0 & 0 & 9 & 81.8 & 1 & 9.1 & 1 & 9.1 \\
\hline Nalidixic acid & 30 & 20 & 66.7 & 7 & 23.3 & 3 & 10 & 7 & 63.6 & 4 & 36.4 & 0 & 0 \\
\hline Gentamicin & 10 & 14 & 46.7 & 9 & 30 & 7 & 23.3 & 1 & 9.1 & 3 & 27.3 & 7 & 63.6 \\
\hline Levofloxacin & 5 & 12 & 40 & 9 & 30 & 9 & 30 & 0 & 0 & 5 & 45.5 & 6 & 54.5 \\
\hline Florophenicol & 30 & 25 & 83.3 & 4 & 13.3 & 1 & 3.3 & 9 & 81.8 & 2 & 18.2 & 0 & 0 \\
\hline Colistin sulphate & 10 & 15 & 50 & 0 & 0 & 15 & 50 & 2 & 18.2 & 1 & 9.1 & 8 & 72.7 \\
\hline Ciprofloxacin & 5 & 10 & 33.3 & 7 & 23.3 & 13 & 43.3 & 0 & 0 & 2 & 18.2 & 9 & 81.8 \\
\hline Amikacin & 30 & 9 & 30 & 9 & 30 & 12 & 40 & 4 & 36.4 & 4 & 36.4 & 3 & 27.3 \\
\hline Flumequine & 25 & 24 & 80 & 5 & 16.7 & 1 & 3.3 & 8 & 72.7 & 3 & 27.3 & 0 & 0 \\
\hline
\end{tabular}

$\%$ : was calculated according to the corresponding number of the tested isolates.

florophenicol (81.2\% for each) (table 6). Meanwhile, high sensitivity to ciprofloxacin (81.8\%) was recorded (table 6). MDR was detected in 5 Salmonella isolates (45.5\%).

\section{DISCUSSION}

Rabbits are highly susceptible to enteric pathogens mainly in the early days after weaning and that may be due to the unestablished intestinal microbiota and illdeveloped digestive performance and the change in gut PH (Pakandl 2009).

Prebiotics are food ingredients that induce the growth or activity of beneficial microorganisms such as bacteria and fungi (Gibson et al 2010). Also, prebiotics and probiotics are well known for modulation of the immune system and improvement of gut health (Hess and Greenberg 2012, Raheel et al 2019). Therefore, the current study was planned to investigate the effects of mannan-oligosaccharide (MOS) supplementation on the coexistence of E. coli and Salmonella species in rabbits naturally infected with intestinal coccidiosis.

In the present work, at the $8^{\text {th }}$ day post treatment with mannan-oligosaccharide (MOS), there was a significant $(P \leq 0.05)$ decrease in both oocyst count $\left(5.33 \pm 0.89 \times 10^{3}\right)$ prevalence of E. coli and Salmonella infections (66.7\% and $26.7 \%$, respectively) in rabbits treated with prebiotic (PT). Meanwhile, the infected untreated group (PC) displayed a significant increase in both oocyst count $(21.67 \pm 0.82$ $\times 10^{3}$ ) and the prevalence of E. coli and Salmonella infections $(86.7 \%$ and $46.7 \%$, respectively). On contrary, the negative control group (NC) displayed only E. coli infection with a prevalence of $46.7 \%$ with no detection for coccidian oocysts and Salmonella. Also, the clinical signs of intestinal coccidiosis were less severe in the PT group 
than in the PC group. These results are consistent with Aboelhadid et al (2021) who found that the use of prebiotic as prophylaxis significantly reduced the prevalence of the E. coli and salmonella infection in rabbits experimentally infected intestinal coccidiosis and diminished the coccidian adverse effect. Pakandl (2009) reported that enteritis caused by coccidia is often accompanied by a marked increase in the number of $E$. coli and other pathogens in the host intestine and hence the interplay between pathogens may be important under field conditions. Similar findings were reported by Kimura et al (1976) as they found an increase in the number of Enterobacteriaceae members during caecal coccidiosis in chicken. Also, Baba et al (1992) suggested that infection with E. tenella can change the balance of competitive adherence of bacteria, allowing more colonisation of S. Typhimurium and Clostridium perfringens. Additionally, Taylor et al (2003) recorded a significant secondary bacterial infection following coccidian infection and subsequently the malabsorption syndrome caused damage to the intestinal mucosa.

MOS prebiotic was derived from the cell wall of Saccharomyces cerevisiae which have the ability to improve gastrointestinal health and performance when added to animal diets (Kocher et al 2004, Miguel et al 2004). Similarly, we found a significant reduction in the prevalence of E. coli and Salmonella in rabbits naturally infected with intestinal coccidiosis, with amelioration in the adverse effects of coccidiosis after administration of MOS prebiotic. Also, Szabóová et al (2012) observed a significant reduction in bacterial and Eimeria oocyst counts in the intestinal tract of rabbits administered a mixture of prebiotic and probiotic as dietary supplementation. In addition, El-Ashram et al (2019) found a significant reduction in the adverse effects of intestinal coccidiosis in rabbits after prebiotic supplementation. Brink et al (2006) found that the growth of many Gram-positive and Gram-negative bacteria was inhibited by the prebiotic treatment. Also, Tran et al (2018) demonstrated that prebiotic supplementation can inhibit enteropathogens such as Salmonella and $E$. coli. Interestingly, Murate et al (2015) realised that the prebiotic additive reduced the occurrence of Salmonella in laying hens but not for broilers. This means that the effects of prebiotic are not constant and more studies are needed to report longitudinal load measure for establishing that prebiotic treatment can decrease the prevalence of $E$. coli and/or Salmonella.

The serogrouping studies of $E$. coli isolates (n=30) revealed that the serogroup $\mathrm{O}_{78}$ was the most predominant with a prevalence of $36.7 \%$, followed by serogroups $\mathrm{O}_{1125}$, $\mathrm{O}_{152}, \mathrm{O}_{158}$ with a prevalence of $20 \%, 13.3 \%$ and $10 \%$, respectively, and then the serogroups $\mathrm{O}_{114}, \mathrm{O}_{115}$ and $\mathrm{O}_{168}$ with a prevalence of $6.7 \%$ for each. These results were similar to those reported by Hassan and Abd Al Azeem (2009), Shahin et al (2011) and Hamed et al (2013).

In the current study, E. coli isolates were completely resistant to neomycin and highly resistant to most of the tested antimicrobials especially florophenicol, sulphamethoxazoltrimethoprim, flumequine, tetracycline, amoxicillin and nalidixic acid. Meanwhile, they were moderately sensitive to colistin sulphate, ciprofloxacin and amikacin. Regarding the high incidences of antimicrobial resistance of $E$. coli isolates in this study, these findings provided more support to the reports of many authors in Egypt (El-Shazly et al 2017, El-Seedy et al 2019, Radwan et al 2021) and worldwide (Makhol et al 2011, Xiaonan et al 2018). Therefore, no single antimicrobial drug was effective by $100 \%$ against E. coli isolates, which might be due to the development of resistance as a result of indiscriminate use of antimicrobials. Moreover, MDR was detected in $90 \%$ of $E$. coli isolates which is in agreement with Radwan et al (2014) as they recorded MDR in $90.4 \%$ of isolates.

On the other hand, Salmonella isolates were highly resistant to sulphamethoxazol-trimethoprim, florophenicol, amoxicillin, flumequine and nalidixic acid and MDR was detected in $45.5 \%$ of the tested isolates. Meanwhile, it revealed high sensitivities against ciprofloxacin, colistin sulphate, gentamicin and levofloxacin. Similar findings were recorded by many authors in Egypt (Ahmed et al 2009, Hassan et al 2018) and worldwide (Kumar et al 2009, Camarda et al 2012, Kim et al 2012, Albuquerque et al 2014, Agrawal et al 2016, Lamas et al 2016). Increasing the occurrence of MDR strains led to antibiotic treatment failure in both humans and animals with the transmission of antibiotic resistance to other bacteria (Suelam and Reda 2015).

In conclusion, the use of Mann prebiotic induced a significant reduction in the prevalence of $E$. coli and Salmonella and at the same time mitigated the adverse effect of coccidiosis in rabbits. E. coli isolates were highly resistant to most of the tested antimicrobials while Salmonella isolates showed variable resistance profiles. In addition, MDR was detected in $90 \%$ of $E$. coli isolates and $45.5 \%$ of Salmonella isolates.

\section{CONFLICT OF INTEREST}

The authors declare no conflict of interest.

\section{ACKNOWLEDGEMENTS}

This work was supported by Researcher supporting Project (RSP2020/3), King Saud University.

\section{REFERENCES}

Abdelhady DH, El-Abasy MA. 2015. Effect of prebiotic and probiotic on growth, immuno-hematological responses and biochemical parameters of infected rabbits with Pasteurella multocida. Benha Vet Med J 28, 40-51.

Aboelhadid SM, Hashem S, Abdel-Kafy E-S, Mahrous LN, Farghly EM, et al. 2021. Prebiotic supplementation effect on Escherichia coli and Salmonella species associated with experimentally induced intestinal coccidiosis in rabbits. PeerJ 9, e10714. 
Agrawal R, Hirpurkar SD. 2016. Prevalence of Salmonella on exterior and interior of fertile eggs from vaccinated breeding hens of different breeds. J Dairy Vet Anim Res 3, 178-183.

Ahmed AM, Younis EEA, Ishida Y, Shimamoto T. 2009. Genetic basis of multidrug resistance in Salmonella enterica serovars Enteritidis and Typhimurium isolated from diarrheic calves in Egypt. Acta Trop 111, 144-149.

Albuquerque AH, Maciel WC, Souza Lopes E, Castro Teixeira RS, Salles RPR, et al. 2014. Presence of Salmonella in one day-old chicks from hatcheries in the Metropolitan Region of Fortaleza, Brazil. Acta Sci Vet 42, 12-22.

Baba E, Wakeshima H, Fukui K, Fukata T, Arakawa A. 1992. Adhesion of bacteria to the cecal mucosal surface of conventional and germ-free chickens infected with Eimeria tenella. Am J Vet Res 53, 194-197.

Bortoluzzi C, Vieira BS, Hofacre C, Applegate TJ. 2019. Effect of different challenge models to induce necrotic enteritis on the growth performance and intestinal microbiota of broiler chickens. Poultry Sci 98, 2800-2812.

Brink M, Todorov SD, Martin JH, Senekal M, Dicks LM. 2006. The effect of prebiotics on production of antimicrobial compounds, resistance to growth at low $\mathrm{pH}$ and in the presence of bile, and adhesion of probiotic cells to intestinal mucous. J Appl Microbiol 100, 813-820.

Camarda A, Pugliese N, Pupillo A, Circella E, Ricci M, et al. 2012. Molecular characterization and antimicrobial resistance of Salmonella Typhimurium from rabbit farms in Southern Italy. World Rabbit Sci 20, 185-194.

Chandran A, Hatha A, Varghese S, Sheeja MK. 2008. Prevalence of multiple drug resistant $E$. coli serotypes in a tropical estuary, India. Microbes Environ 23, 153-158.

CLSI, Clinical and Laboratory Standards Institute. 2016. Performance standards for antimicrobial susceptibility testing. $26^{\text {th }}$ ed. CLSI supplement M100-S, Wayne, USA.

Collee JG, Fraser AG, Marmion BP, Simmons A. 1996. Mackie and MacCartney Practical Medical Microbiology. $14^{\text {th }}$ ed. Churchill Livingstone, New York, USA, Pp 131-151.

Croxen MA, Law RJ, Scholz R, Keeney KM, Wlodarska M, et al. 2013. Recent advances in understanding enteric pathogenic Escherichia coli. Clin Microbiol Rev 26, 822-880.

Dalle ZA, Szendro Z. 2011. The role of rabbit meat as functional food. Meat Sci 88, 319-331.

Dorota K, Paweł B, Paweł N, Jerzy K. 2012. Natural alternatives to coccidiostats in rabbit nutrition. Ann Anim Sci 12, 561-574.

Donalson LM, McReynolds JL, Kim WK, Chalova VI, Woodward CL, et al. 2008. The influence of a fructooligosaccharide prebiotic combined with alfalfa molt diets on the gastrointestinal tract fermentation, Salmonella enteri-tidis infection, and intestinal shedding in laying hens. Poultry Sci 87, 1253-1262.

Eckert J, Taylor M, Licois D, Coudert P, Catchpole J, et al. 1995. Identification of Eimeria and Isospora species and strains: Morphological and biological characteristics. In: Eckert J, Braun R, Shirley MW, Coudert P (eds). Biotechnology. Guidelines on Techniques in Coccidiosis Research. Office for Official Publications of the European Communities, Luxembourg. Pp 103-119.

El-Abasy MA. 2002. Studies on sugar cane extract for control of chicken diseases. PhD Dissertation, Tokyo University, Tokyo, Japan.

El-Ashram AS, Aboelhadid SM, Abdel-Kafy EM, Hashem SA, Mahrous LN, et al. 2019. Prophylactic and therapeutic efficacy of prebiotic supplementation against intestinal coccidiosis in rabbits. Animals 9, 965 .

El-Ashram S, Aboelhadid SM, Abdel-Kafy EM, Hashem SA, Mahrous LN, et al. 2020. Investigation of pre- and post-weaning mortalities in rabbits bred in Egypt, with reference to parasitic and bacterial causes. Animals 10, 537.

El-Seedy FR, Abed AH, Wafaa MMH, Bosila AS, Mwafy A. 2019. Antimicrobial resistance and molecular characterization of pathogenic E. coli isolated from chickens. J Vet Med Res 26, 280-292.
El-Shazly DA, Nasef SA, Mahmoud, FF, Jonas D. 2017. Expanded spectrum $\beta$-lactamase producing Escherichia coli isolated from chickens with colibacillosis in Egypt. Poult Sci 96, 2375-2384.

Ferket PR, Parks CW, Grimes JL. 2002. Benefits of dietary antibiotic and mannano-oligosaccharide supplementation for poultry. Proceeding of the Multi-State Poultry Meeting, Eagan, Minnesota, USA.

Gibson GR, Scott KP, Rastall RA, Tuohy KM, Hotchkiss A, et al. 2010. Dietary prebiotics: current status and new definition. Food Sci Technol Bull Func Foods 7, 1-19.

Grimont PA, Weill FX. 2007. Antigenic formulae of the Salmonella serovars. $9^{\text {th }}$ ed. World Health Organization Collaborating Centre for Reference Research on Salmonella, Institute Pasteur, Paris, France.

Hamed AM, Eid AAM, El-Bakrey RMM. 2013. A review of rabbit diseases in Egypt. Wartazoa 23, 185-194.

Hassan SA, Abd Al Azeem MW. 2009. Determination of virulence gene markers and antimicrobial resistance in Escherichia coli isolated from rabbit in Egypt. Glob Vet 3, 260-267.

Hassan WH, Abed AH, Thabet A, El Nady EAM. 2018. Genetic analysis of multidrug resistant Salmonella isolated from broiler chickens. $J$ Vet Med Res 25, 121-131.

Hess JR, Greenberg NA. 2012. The Role of Nucleotides in the Immune and Gastrointestinal Systems Potential Clinical Applications. Nutr Clin Prac 27, 281-294.

Kim MS, Lim TH, Jang JH, Lee DH, Kim BY, et al. 2012. Prevalence and antimicrobial resistance of Salmonella species isolated from chicken meats produced by different integrated broiler operations in Korea. Poult Sci 91, 2370-2375.

Kimura N, Mimura F, Nishida S, Kobayashi A. 1976. Studies on the relationship between intestinal flora and cecal coccidiosis in chicken. Poult Sci 55, 1375-1383.

Kocher A, Spring P, Hooge D. 2004. Rabbits may respond positively to dietary MOS. Feedstuffs 76, 1-3.

Kocher A, Garcia, P, Tucker LA. 2005. Effects of Bio-Mos for laying hens 20-52 weeks under commercial conditions. Proceedings of the Alltech's 21st Annual Symposium on Nutritional Biotechnologies in the Feed and Food Industries, Lexington, KY, USA, Pp 316-317.

KumarY, Sharma A, Mani KA. 2009. High level of resistance to nalidixic acid in Salmonella enterica serovar Typhi in Central India. J Infect Dev Ctries 3, 467-469.

Lamas A, Fernandez-No IC, Miranda JM, Vazquez B, Cepeda A, et al. 2016. Prevalence, molecular characterization and antimicrobial resistance of Salmonella serovars isolated from northwestern Spanish broiler flocks (2011-2015). Poult Sci 95, 2097-2105.

Langan GP, Lohmiller JJ, Swing SP, Wardrip CL. 2000. Respiratory diseases of rodents and rabbits. Vet Clin North Am Small Anim Pract 30, 1309-1335.

Lennox AM, Kelleher S. 2009. Bacterial and parasitic diseases of rabbits. Vet Clin North Am Exot Anim Pract 12, 519-530.

Madlala T, Okpeku M, Adeleke MA. 2021. Understanding the interactions between Eimeria infection and gut microbiota, towards the control of chicken coccidiosis: a review. Parasite 28, 48 .

Makhol BM, Habreh N, Sakural K. 2011. Antibiotic resistance of E.coli isolated from poultry in Syria. Assiut Vet Med J 57, 265-275.

Miguel JC, Rodriguez-Zas SL, Pettigrew JE. 2004. Efficacy of a mannanoligosaccharide (Bio- Mos $®$ ) for improving nursery pig performance. J Swine Health Prod 12, 296-307.

Murate LS, Fernanda GP, de Almeida AM, Berchieri A Jr, Shimokomaki M 2015. Efficacy of prebiotics, probiotics and synbiotics on laying hens and broiler challenged with Salmonella Enteritidis. J Poult Sci 52, 52-56

Ogolla KO, Gathumbi PK, Waruiru RM, Okumu PO, Chebet J, et al. 2018. Efficacy of sulphachloropyrazine, amprolium hydrochloride, trimethoprim-sulphamethoxazole, and diclazuril against experimental and natural rabbit coccidiosis. J Vet Med 2018, 5402469.

Pakandl M. 2009. Coccidia of rabbit: A review. Folia Parasitologica $56,153-166$ 
Pakandl M, Hlaskova L. 2007. The reproduction of Eimeria flavescens and Eimeria intestinalis in suckling rabbits. Parasitol Res 101, 1435-1437.

Papeschi C, Fichi G, Perrucci S. 2013. Oocysts excretion of three intestinal Eimeria species in female rabbits. World Rabbit Sci 21, 77-83.

Quinn PJ, Markey BK, Carter ME, Donnelly WJC, Leonard FC. 2002. Veterinary microbiology and microbial disease. Blackwell Science, Oxford, UK.

Radwan IA, Hassan HS, Abd-Alwanis SA, Yahia MA. 2014. Frequency of some virulence associated genes among multidrug-resistant Escherichia coli isolated from septicemic broiler chicken. Int J Adv Res 2, 867-874.

Radwan IA, Abd El-Halim MW, Abed AH. 2021. Molecular characterization of antimicrobial resistant Escherichia coli isolated from broiler chickens. J Vet Med Res 27, 128-142.

Raheel IAR, Orabi A, Salam SH, Abed AH, Fouad IA, et al. 2019 Immune-modulating effects of Aviboost ${ }^{\circledR}$ nucleotides on the intestinal epithelium of Broiler chickens. Inter J Vet Sci 8, 89-95.

Rashwan AA, Marai IFM. 2000. Mortality in young rabbits: a review. World Rabbit Sci 8, 111-124.

Saravia M, Segovia C, Valderrama K, Santander J. 2017. Colibacillosis in a New Zealand white rabbit (Oryctolagus cuniculus). J Infect Dev Ctries 11, 203-206.

Schito ML, Barta JR, Chobotar B. 1996. Comparison of four murine Eimeria species in immunocompetent and immunodeficient mice. $J$ Parasitol 82, 255-262.

Shahin AM, Lebdah MA, Ali GRM. 2011. Escherichia coli as an etiological agent of mucoid enteropathy in rabbits. Researcher 3, 8-16.

Sohail M, Ijaz A, Yousaf M, Ashraf K, Zaneb H, et al. 2010. Alleviation of cyclic heat stress in broilers by dietary supplementation of mannan-oligosaccharide and Lactobacillus-based probiotic: Dynamics of cortisol, thyroid hormones, cholesterol, C-reactive protein, and humoral immunity. Poultry Sci 89, 1934-1938.

Suelam IIA, Reda LM. 2015. Isolation and identification of Salmonella enterica Typhimurium from rabbits. Egy J Rabbit Sci 25, 137-148.

Szabóová R, Lauková A, Chrastinová l', Strompfová V, Monika SP, et al. 2012. Beneficial effect of plant extracts in rabbit husbandry. Acta Vet Brno 81, 245-250.

Taylor MA, Catchpole J, Marshall J, Marshall, RN, Hoeben D. 2003. Histopathological observations on the activity of diclazuril (Vecoxan) against the endogenous stages of Eimeria crandallis in sheep. Vet Parasitol 116, 305-314.

Tran THT, Everaert N, Bindelle J. 2018. Review on the effects of potential prebiotics on controlling intestinal enteropathogens Salmonella and Escherichia coli in pig production. J Anim Physiol Anim Nutr (Berl)102, 17-32.

Waldroup PW, Oviedo-Rondon EO, Fritts CA. 2003. Comparison of BioMos ${ }^{\circledR}$ and antibiotic feeding programs in broiler diets containing copper sulfate. Int J Poult Sci 2, 28-31.

Walsh JL, Percival A, Turner PV. 2017. Efficacy of blunt force trauma, a novel mechani-cal cervical dislocation device, and a non-penetrating captive bolt device for on-farm euthanasia of pre-weaned kits, growers, and adult commercial meat rabbits. Animals 7, 100.

Xiaonan Z, Yang J, Ju Z, Chang W, Sun S. 2018. Molecular characterization of antimicrobial resistance in Escherichia coli from Rabbit farms in Taiwan, China. BioMed Res Int 2018, 8607647.

Zahraei T, Mahzouniehand M, Khaksar E. 2010. Detection of Salmonella serovars in zoo and pet reptiles, rabbits, and rodents in Iran by culture and PCR methods. Comp Clin Pathol 19, 199-202. 